\title{
Mutual tolerance or reproductive competition? Patterns of reproductive skew among male redfronted lemurs (Eulemur fulvus rufus)
}

\author{
Peter M. Kappeler • Markus Port
}

Received: 25 October 2007 /Revised: 25 February 2008 / Accepted: 27 February 2008 /Published online: 17 April 2008

(C) The Author(s) 2008

\begin{abstract}
The social organization of gregarious lemurs significantly deviates from predictions of the socioecological model, as they form small groups in which the number of males approximately equals the number of females. This study uses models of reproductive skew theory as a new approach to explain this unusual group composition, in particular the high number of males, in a representative of these lemurs, the redfronted lemur (Eulemur fulvus rufus). We tested two central predictions of "concession" models of reproductive skew theory, which assume that subordinates may be allowed limited reproduction by dominant group members as an incentive to remain in the group, thereby increasing the group's overall productivity. Accordingly, relatives are predicted to receive less reproduction than non-relatives, and the overall amount of reproductive concessions given to subordinates is predicted to increase as the number of subordinates increases. In addition, we tested whether the number of females in a
\end{abstract}

Electronic supplementary material The online version of this article (doi:10.1007/s00265-008-0577-5) contains supplementary material, which is available to authorized users.

Both Peter M. Kappeler and Markus Port contributed equally to this paper.

Communicated by C. Nunn

P. M. Kappeler $(\varangle) \cdot$ M. Port

Department of Behavioral Ecology and Sociobiology,

German Primate Center,

Kellnerweg 4,

37077 Göttingen, Germany

e-mail: pkappel@gwdg.de

P. M. Kappeler • M. Port

Department of Sociobiology and Anthropology,

Institute of Zoology and Anthropology,

Berliner Str. 28,

37073 Göttingen, Germany group, a variable not previously incorporated in reproductive skew theory, affected reproductive skew among males. Using microsatellite analyses of tissue DNA, we determined paternities of 49 offspring born into our study population in Kirindy forest (western Madagascar) since 1996 to determine patterns of male reproductive skew to test these predictions. Our analyses revealed remarkable reproductive skew, with $71 \%$ of all infants being sired by dominant males, but both predictions of reproductive skew models could not be supported. Instead, the number of females best predicted the apportionment of reproduction among the males in this species, suggesting that current reproductive skew models need to incorporate this factor to predict reproductive partitioning among male primates and perhaps other group-living mammals.

Keywords Sexual selection · Reproductive skew - Primates · Paternity Eulemur fulvus

\section{Introduction}

The adaptive basis of variation among mammalian social systems has been a major focus of socioecological research from its inception (Crook and Gartlan 1966; Clutton-Brock 1989). According to the socioecological model, the distribution of females is primarily determined by the distribution of risks and resources in the environment, whereas males distribute themselves in response to the spatiotemporal distribution of receptive females (Emlen and Oring 1977). From a male's perspective, reproductive success is mainly limited by access to mates (Bateman 1948; Trivers 1972). Therefore, whenever females form social units that are small enough to be defended by a single male, males should try to monopolize females via the 
exclusion of rivals (Kappeler 1999). As a consequence, small groups of females are expected to be monopolized by one adult male (Clutton-Brock 1989).

Among gregarious primates, this prediction was supported by studies of cercopithecine monkeys in which groups of less than six females are usually monopolized by a single male (Andelman 1986). In contrast, the gregarious lemurs of Madagascar markedly differ from this prediction, as they usually form groups with even or male-biased sex ratios, even though groups do on average not contain more than five females (Kappeler 2000). This deviation from predictions of the socioecological model has not yet been explained in a satisfactory manner (but see, e.g., van Schaik and Kappeler 1996). However, previous studies of the evolution of primate social systems focused on male-male competition for mates, whereas little emphasis has yet been laid on male behavior beyond competition. In fact, dominant males could also profit from the presence of additional males via group augmentation benefits (e.g., van Schaik and van Noordwijk 1989; Packer et al. 1988), so that the benefits derived from the presence of additional males may exceed the costs the latter impose due to lost paternity. Therefore, selection may favor increased mutual tolerance among males.

Vehrencamp (1983a, b) first integrated this assumption into a quantitative model of group living. This model was later extended by Reeve and Ratniecks (1993) who assumed that the dominant group member completely controls the reproductive opportunities within a group but voluntarily gives a share of reproduction to subordinates as an incentive to remain in the group, as the latter's presence increases the dominant's fitness. Accordingly, a subordinate's share of reproduction is determined by its prospects for solitary breeding outside the dominant's territory, its contribution to the group's productivity, its relatedness to the dominant, and its relative fighting ability. This theoretical framework allowed for quantitative tests of the evolution of group living that considered not only competition among same-sexed group members but also their benefits from peaceful association.

During the last decade, Reeve and Ratnieck's "concession" model passed through several extensions, some of which allowed subordinates to choose among several dominants (the "bidding game", Reeve 1998) or to queue for dominant status (Kokko and Johnstone 1999), and the original two-player version was extended to larger associations (Johnstone et al. 1999; Reeve and Emlen 2000). However, it has been criticized that the most eminent assumption of the concession model, the dominant's ability to monopolize reproduction, is unlikely to hold for the majority of animal societies (CluttonBrock 1998). Therefore, alternative models have been developed in which the dominant lacks control over the allocation of reproduction. Instead, reproductive skew within groups is either a consequence of direct competition (the "tug-of-war model", Reeve et al. 1998), which decreases group productivity or a consequence of the subordinate's restraint from reproduction due to the threat of being evicted from the group (the "restraint" model, Johnstone and Cant 1999). In terms of the variables thought to affect reproductive skew, these latter models make predictions that are different from, or even opposite to, those derived from the concession model. Finally, Johnstone (2000) and Reeve and Shen (2006) reconciled the mainstream models, but their synthetic approaches remain to be tested and continue to be debated (e.g., Nonacs 2006, 2007).

Most tests of reproductive skew theory were conducted with small colonies of social insects (reviewed in Reeve and Keller 2001), but an increasing number of studies have used vertebrate model organisms (fish, e.g., Stiver et al. 2005; Heg et al. 2006; birds, e.g., Jamieson 1997; Haydock and Koenig 2003; Williams 2004; mammals, e.g., Clutton-Brock et al. 2001; Widdig et al. 2004; Kutsukake and Nunn 2006). Most of these vertebrate studies concluded that a "limited control" scenario best explains the apportionment of reproduction, whereas only a few studies supported the concession model in vertebrates (McRae 1996; Jamieson 1997).

The aim of this study was to test models of reproductive skew theory in redfronted lemurs (Eulemur fulvus rufus) to illuminate the evolution of group size and composition in this species. In particular, evidence in support of the concession model would indicate the importance of male-male cooperation as an ultimate reason for the unusual social organization of these lemurs. Their small groups with even sex ratios make redfronted lemurs a particularly appropriate species for tests of reproductive skew theory. In addition, one male clearly dominates all other males and monopolizes the majority of social contacts and matings with females (Ostner and Kappeler 1999) but also benefits from the presence of subordinates as groups with more males are less likely to be taken over by potentially infanticidal intruders (Ostner and Kappeler 2004). Therefore, an important assumption of the concession model seems to be fulfilled in this species. Preliminary parentage analyses revealed that six out of nine infants were sired by dominant males (Wimmer and Kappeler 2002); the question remains whether the observed skew is the consequence of concessions given by the dominant or his inability to prevent subordinates from mating.

Using demographic and paternity data, we test two of the predictions of reproductive skew theory (summarized in Table 1): First, according to the concession model, relatives of a dominant are expected to gain less reproduction than non-relatives (because relatives profit from inclusive fitness), whereas according to the restraint model, relatives are predicted to gain more reproduction (because the eviction of relatives is costlier to the dominant). The tugof-war model, in contrast, predicts skew to be insensitive to relatedness. Second, according to the tug-of-war model, an 
Table 1 Predicted and observed relationships between the number of males, the number of females and relatedness (between dominant and subordinates) and the subordinates' fraction of reproduction according to three reproductive skew models and the priority of access model

\begin{tabular}{lllll}
\hline Variable & Concession & Restraint & Tug-of-war & Priority of access \\
\hline Number of males & $+^{\mathrm{a}}$ & No prediction & + & Observed \\
Number of females & No prediction & No prediction & No prediction & $+^{\mathrm{b}}$ \\
Relatedness & - & + & 0 & No prediction \\
\hline
\end{tabular}

+: positive relationship, - : negative relationship, 0 : no relationship predicted

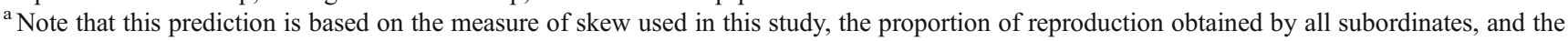
assumption that group productivity is a decelerating function of group size.

${ }^{\mathrm{b}}$ This prediction assumes reproductive synchrony to increase with female number (note that redfronted lemurs are highly seasonal breeders).

increase in the number of males within a group translates into an increase in the number of competitors. Therefore, the dominant's share of reproduction is predicted to decrease with an increasing number of males. Unfortunately, predictions of the concession model are not that straightforward and depend on within-group relatedness (Johnstone et al. 1999; Reeve and Emlen 2000) as well as on the chosen measure of skew (Port, unpublished data). In this study, we measured skew as the total proportion of reproduction obtained by all subordinates within a group (see "Materials and methods"). If we assume group productivity to be a decelerating function of group size, we predict this measure of skew to increase as the number of subordinates increases, even though the concessions required by a single subordinate may decrease in some cases (Reeve and Emlen 2000). For instance, due to the concave curvature of the productivity function, two subordinates together will require a larger share of reproduction than one alone, although each of them may be satisfied with a yet lower personal share in an association of three, as compared to an association of two subordinates.

Using demographic data also enabled us to measure the impact of the number of females in a group on male reproductive skew. This variable has not yet been incorporated in reproductive skew theory, even though several primate studies revealed that the number of females in a group may set a limit to a dominants' ability to monopolize matings, especially if female receptive periods overlap (e.g., Andelman 1986; Nunn 1999; Cords 2000). Accordingly, the "priority-of-access" model (Altmann 1962) predicts that more low-ranking males get to mate as the number of synchronously receptive females increases (see Alberts et al 2003). We cannot directly measure reproductive synchrony in this study, but as redfronted lemurs are highly seasonal breeders, we predict reproductive skew to decrease with an increasing number of females within groups. Note that in contrast to the tug-of-war model, which focuses on the energy allocated by males to their struggle over reproduction, the priority-of-access model reflects a dominant's inability to monopolize several females at the same time.

\section{Materials and methods}

\section{Study population and data collection}

This study is part of an ongoing long-term study conducted in Kirindy Forest, a dry deciduous forest located within a forestry concession operated by the Centre Formation Professionelle Forestière (CFPF) Morondava, approximately $60 \mathrm{~km}$ northeast of Morondava, western Madagascar. For a detailed description of the forest, see Sorg et al. (2003).

All study animals belonged to one of five groups (A, B, F, I, J) living in a 60-ha study area, which is part of the German Primate Center field site at Kirindy. Unmarked individuals that were either born into or that have migrated into our study population have been regularly captured since 1996 and marked with unique nylon collars or radio collars. In addition, small tissue samples $\left(2-3 \mathrm{~mm}^{2}\right)$ from the ear were taken from anaesthetized animals and transferred to $70-90 \%$ ethanol for later DNA extraction. All groups have also been subjected to daily or at least weekly demographic censuses since 1996 by local field assistants. Dominance relationships among males were assessed on the basis of decided agonistic interactions during behavioral observations carried out in 1997 (Ostner and Kappeler 1999), 1999-2000 (Ostner 2004), and 20042006 (Port, unpublished data).

Group size (excluding newborn offspring) of the five study groups ranged between 4 and 11 individuals (mean= $6.73)$, including two to five (mean=3.37) adult males and one to three $($ mean $=2.26)$ adult females (Table 2). Redfronted lemur groups usually consist of a core of related females (Wimmer and Kappeler 2002); adult males are either natal males that delayed their dispersal (the number of which ranged in our study between 0 and 2 ; mean $=0.52$ ) or immigrants (range 2-4; mean $=2.85$ ). Reproduction in redfronted lemurs is highly seasonal. Mating behavior is largely restricted to a few weeks in May/June (Ostner and Kappeler 2004), during which, a female's fertile period is limited to 1-3 days (Boskoff 1978). 
Table 2 Group composition, number of offspring born, and subordinates' share of reproduction in five redfronted lemur groups from 1996 to 2004

\begin{tabular}{|c|c|c|c|c|c|c|}
\hline Group $^{\mathrm{a}}$ & Year & Number offspring & Number males & Number females & Subordinates share ${ }^{\mathrm{b}}$ & Subordinates share (class) \\
\hline A1 & 1996 & 2 & 3 & 2 & $1 / 2$ & Medium \\
\hline A1 & 1997 & 2 & 3 & 2 & 0 & Low \\
\hline A1 & 1998 & 1 & 4 & 2 & 0 & Low \\
\hline A1 & 1999 & 2 & 4 & 2 & 0 & Low \\
\hline $\mathbf{A 2}$ & 2002 & 1 & 5 & 2 & 0 & Low \\
\hline $\mathbf{A 2}$ & 2003 & 2 & 5 & 2 & 0 & Low \\
\hline $\mathbf{A 2}$ & 2004 & 2 & 4 & 2 & $1 / 2$ & Medium \\
\hline B1 & 1996 & 3 & 4 & 3 & $2 / 3$ & Medium \\
\hline B1 & 1997 & 2 & 3 & 3 & 0 & Low \\
\hline B1 & 1998 & 2 & 4 & 2 & 0 & Low \\
\hline B1 & 1999 & 1 & 4 & 3 & 1 & High \\
\hline B2 & 2001 & 1 & 4 & 2 & 0 & Low \\
\hline B2 & 2002 & 3 & 3 & 3 & 0 & Low \\
\hline B2 & 2003 & 2 & 3 & 3 & 1 & High \\
\hline B2 & 2004 & 3 & 4 & 3 & $2 / 3$ & Medium \\
\hline $\mathrm{F} 1$ & 1997 & 1 & 3 & 2 & $?$ & $?$ \\
\hline F2 & 1999 & 2 & 3 & 2 & 0 & Low \\
\hline F2 & 2000 & 2 & 4 & 2 & 0 & Low \\
\hline F2 & 2001 & 1 & 3 & 2 & 0 & Low \\
\hline F2 & 2002 & 1 & 4 & 3 & 1 & High \\
\hline F3 & 2003 & 2 & $?$ & $?$ & $2 \times \mathrm{EGP}^{\mathrm{c}}$ & $?$ \\
\hline F4 & 2004 & 1 & 2 & 1 & $?$ & $?$ \\
\hline I1 & 1996 & 1 & $?$ & $?$ & $?$ & $?$ \\
\hline I1 & 1997 & 1 & $?$ & $?$ & $?$ & $?$ \\
\hline $\mathrm{J} 1$ & 1997 & 1 & $?$ & $?$ & $?$ & $?$ \\
\hline $\mathrm{J} 1$ & 1999 & 2 & 4 & 2 & $?$ & $?$ \\
\hline $\mathrm{J} 2$ & 2001 & 1 & 3 & 2 & $?$ & $?$ \\
\hline $\mathrm{J} 2$ & 2002 & 1 & 2 & 2 & $?$ & $?$ \\
\hline $\mathbf{J 3}$ & 2003 & 1 & 2 & 3 & 1 & High \\
\hline J3 & 2004 & 2 & 2 & 2 & 0 & Low \\
\hline
\end{tabular}

Only group years in which at least one infant survived until capture are shown; only group years indicated in bold letters entered the analysis of reproductive skew (see notes below).

${ }^{a}$ Numbers indicate tenures of different dominants (or groups of males, if dominance relationships were not known).

b The subordinates' share of reproduction could only be determined if dominance relationships could be inferred from behavioral observations. If in a given year the animals were not observed, we assumed that the male that was dominant in the year of observation was also dominant in the year before. In some years, however, information about dominance relationships was too sparse to reliably classify individuals as dominant or subordinate.

${ }^{\mathrm{c}}$ Extra-group paternity.

Paternity analyses

Sixty-nine infants were born into our study population between 1996 and 2004, 49 of which survived until they were old enough (about 5 months) to be captured. DNA was extracted from tissue samples using QIAamp ${ }^{\circledR}$ tissue kits (Quiagen) and analyzed at 11 nuclear markers (microsatellites): Efr 05, Efr 08, Efr 24, Efr 30, Efr 37, Efr 56, Efr 80 (for details, see Jekielek and Strobeck 1999), I3, L2, Efr 02, and Efr F9 (for details, see Wimmer and Kappeler 2002). The mean number of alleles per locus was 9.6 (range 5-17), and the mean observed heterozygosity was $0.79( \pm 0.07)$. Because mothers of offspring were usually known, the total exclusionary power of the 11 markers was 0.99996 .
Paternity analyses were performed using the program CERVUS 2.0 (Marshall et al. 1998). Candidate males were excluded from paternity if they showed at least one heterozygous mismatch with a given mother-offspring pair. In addition, CERVUS calculates log-likelihood ratios (LOD scores), which represent the likelihood of paternity of a candidate male relative to a randomly chosen male. The difference between the LOD scores of the most likely and the second most likely male is expressed as the $\Delta$ statistic. Confidence intervals of this statistic are assessed in a large number of paternity test simulations that require locusspecific allele frequency data for the population of interest and some additional population parameters, which were defined as follows: For each group and each year, we 
considered the probability that in addition to the resident males, one unsampled male could have sired offspring. This in turn translates to a proportion of sampled candidate males of 0.77 . The mean number of candidate fathers per group and year was set to five (mean number of resident males plus one unsampled male, rounded up); the mean proportion of loci typed was 0.97 . Error rate, estimated from known mother-offspring pairs, was 0.002 , and was set to 0.01 . A total of 50,000 simulation cycles were performed.

\section{Relatedness analyses}

Pairwise relatedness coefficients were calculated with RELATEDNESS 5.0.8 (based on a method of Queller and Goodnight 1989) using the same microsatellite data. If, according to the concession or restraint model, individuals treat relatives and non-relatives differentially, individuals have to be able to perceive each other's relatedness. Relatedness coefficients are continuous measures of the proportion of alleles identical by descent that are shared between pairs of individuals (Blouin 2003). However, it is unlikely that animals perceive relatedness on a continuous scale. Instead, they are more likely to distinguish discrete relatedness classes dependent on the social system in which they live. Redfronted lemurs are probably not able to distinguish full sibs from maternal half sibs or paternal half sibs from animals that simply originate from the same group. But they should be able to discriminate individuals that stem from the same group (and are thus likely to be related) from individuals that stem from a different group (and are likely to be unrelated).

To account for the animals' inability to perceive relatedness on a continuous scale, we created the following discrete relatedness classes for our analyses: parent-offspring (PO), full sib (FS), half sib (HF), same origin (SO; animals that have no shared parent but originate from the same group), and unrelated (UR). We used relatedness information derived from pedigrees and previous analyses of mitochondrial haplotypes (Wimmer 2000, Wimmer and Kappeler 2002) as well as from our paternity analyses to calculate relatedness coefficients of 90 known PO pairs, 21 known FS pairs, 72 known HS pairs, 37 known SO pairs, and 100 randomly drawn pairs of individuals that were supposed to be unrelated. By this means, we obtained the distribution of relatedness coefficients within each class and, as suggested by Blouin et al. (1996), used the midpoint between two distributions as the cutoff value for the classification of unknown pairs based solely on their relatedness coefficients.

However, due to high variance in marker-based relatedness estimates (van de Casteele et al. 2001), a high misclassification rate is to be expected (Blouin et al. 1996). For every $r$ value that entered our analysis, we therefore estimated the probability that it belonged to another distribution than the one it was assigned to by the method of Blouin et al. (1996) using the following procedure: relatedness coefficients within all classes (except for FS where sample size was too small) were normally distributed (goodness of fit $\chi^{2}$ : PO: $\chi^{2}=4.15$, $d f=4, p=0.39$; HS: $\chi^{2}=3.82, d f=4, p=0.43$; SO: $\chi^{2}=3.74$, $d f=1, p=0.06$; UR: $\chi^{2}=4.11, d f=2, p=0.13$ ). For every $r$ value in question, we therefore obtained a corresponding $z$ score for each of the five distributions, hence the cumulative probabilities of this $r$ belonging to each class. Specifically, for $r$ values classified as "unrelated," we were interested in the probability $p$ that these coefficients belonged to the adjacent (higher) SO distribution, and for $r$ values assigned to one of the "related" classes, we were interested in the probability $1-p$ that these coefficients belonged to the (lower) UR distribution. This way, we effectively restricted our analysis to a comparison of related vs. unrelated animals. We did so because we believe that this is the most basic distinction that the animals are able to make and because our sample size precluded a more detailed analysis (see "Results").

\section{Measures of reproductive skew}

More than 20 indices to measure reproductive skew have been proposed in the literature (e.g., Kokko et al. 1999; Nonacs 2003). To test the relationship between both male and female group size and skew, our aim was to measure skew in each group for each reproductive season. However, as the number of offspring born in a given season was very small, the calculation of such an index would be highly susceptible to chance effects in male reproductive success (see Kokko et al. 1999). Instead, using the statistics described below, we tested whether the probability that offspring was sired by subordinates was affected by either male or female group size. Our measure of reproductive skew was the relative share of reproduction obtained by all subordinates, which is equivalent to the dominant's proportion of reproduction. This measure of skew has been used in some previous studies (e.g., Hannonen and Sundström 2003; Kutsukake and Nunn 2006), and the predictions of most N-person models are based on it (Reeve et al 1998; Reeve and Emlen 2000; but see Johnstone et al. 1999). However, it has the disadvantage that it does not describe the distribution of reproduction among subordinates and does therefore not capture all aspects of reproductive skew.

\section{Statistical analyses}

We analyzed the relationship between the subordinates' proportion of reproduction and group size using an ordered logistic regression model. This is an extension of standard logistic regression in which the dependent variable is allowed to be ordinally scaled (Long 1997). The dependent variable was the proportion of reproduction attributable to 
subordinates, the value of which depended on the number of infants born in a given season (range 1-3), yielding the corresponding discrete values of $0,1 / 3,1 / 2,2 / 3$, and 1 . Given the rarity of some values $(1 / 3,2 / 3)$ and the fact that not all values $(1 / 3,1 / 2,2 / 3)$ could be obtained every season, we classified the subordinates' reproductive success as "low" if none of the infants of a given season were sired by them, as "medium" if $1 / 3,1 / 2$, or $2 / 3$ of the infants were sired by them, and as "high" if all infants were sired by subordinates. Hence, we obtained an ordinally scaled dependent variable with three classes. The number of females and the number of adult males present during the mating season entered our model as predictor variables. In a first model, we did not distinguish between natal males and immigrants because natal males were also observed to copulate with more distantly related females (e.g., their aunts). In a second model, we excluded natal males from the analysis. Because both models yielded very similar results, only the results of the model including natal males are reported here. The models were calculated using SPSS 12.0.

While significance testing of the overall model as well as of the regression coefficients is straightforward, a more detailed interpretation of the regression coefficients is complicated by the nonlinearity of the model and its ordinally scaled dependent variable. We therefore provide a more detailed description of the model in the Appendix and stress that the quantitative impact of a regression coefficient on the dependent variable can not directly be estimated from the magnitude of this coefficient. Instead, Eq. 2 (see Appendix) has to be used to calculate the probability of the dependent variable to be of one of the three classes (e.g., subordinates having "high" reproductive success), given the appearance of the independent variables incorporated in the model.

Finally, to test the relationship between reproductive skew and relatedness, we tested for all offspring sired by subordinates whether subordinates related with the dominant were more likely to sire offspring than non-relatives. This analysis was performed using a binomial test in which the expected probability that infants are sired by relatives was derived from the proportion of relatives present in the respective groups.

\section{Results}

Paternities

Paternity analyses were carried out for 49 infants born between 1996 and 2004. Paternity could be assigned to 47 of them; in all these cases, all but one male showed at least one heterozygous mismatch with a given mother-offspring dyad. According to the CERVUS $\Delta$-criterion, 45 paternities could be assigned with $98 \%$ confidence and two paternities with $95 \%$. In two cases, paternity could not be assigned. Both infants were born in the same group in the same year (F3, see Table 2) in which male group composition was unstable. None of the males present before or after the change in group composition could be assigned paternity; hence, both infants were probably sired by extra-group males. One infant was sired by a natal male (group F4), an older brother of the infant's mother. This group contained no immigrant males during that mating season. A detailed table of all paternities is available in the Electronic ESM.

Of the 47 cases in which paternity could be assigned, dominance relationships between males could be determined in 38 cases. Twenty-seven (71\%) of these 38 infants were sired by dominants, whereas only $11(29 \%)$ were sired by subordinates. Given the fact that over all mating seasons the number of subordinates was on average 2.57 times higher than the number of dominants, the observed distribution of paternities between both classes of males was significantly different from random mating $\left(\chi^{2}=34.94\right.$, $d f=1, p<0.001)$. On an individual level, dominants sired 6.31 times as many offspring per individual and season as did subordinates (Fig. 1).

\section{Reproductive skew and group size}

Table 2 shows the number of adult males and females for each group and each year of the study along with the proportion of offspring sired by subordinates. The overall ordered logit model with both the number of males and the number of females as continuous predictor variables was significant ( $\log$ likelihood $=-8.52, G=9.83, d f=2, p=$ 0.007 ), but only the number of females affected the proportion of offspring sired by subordinates significantly $\left(\widehat{\beta}_{\mathrm{f}}=3.11, W=7.51, d f=1, p=0.006\right)$. Thus, as the number

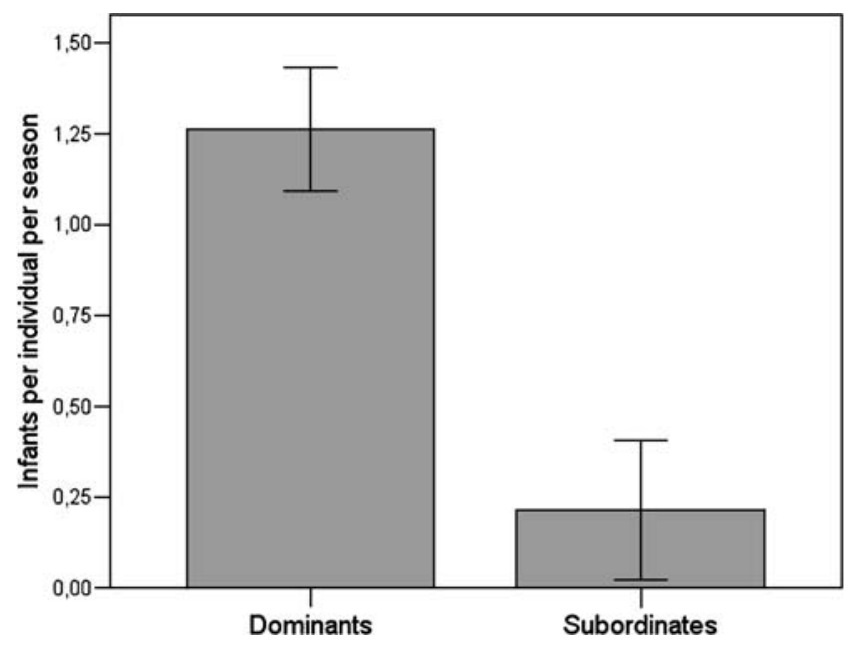

Fig. 1 Reproductive success of dominants and subordinates: mean \pm $95 \%$ confidence interval number of infants sired per season per individual 
of females increased, subordinates were more likely to sire a larger proportion of offspring. The number of males had no significant effect (Table 3). Because the number of males was also not correlated with the number of females $\left(r_{\mathrm{s}}=-0.2, p=0.4\right)$, multicollinearity among independent variables had presumably no effect on our model.

A more detailed impression of the magnitude that an increase in the number of females had on the subordinates' reproductive success can be gained from Eq. 2 (see Appendix). Using the parameters derived from the model and setting the number of males at its mean ( 3.57 for the group years tested in the model), the probabilities of subordinates having low, medium, or high reproductive success given various numbers of females can be calculated (Table 4). Results indicate that subordinates had virtually no chance of siring offspring if there is only one female in the group. The probability to father offspring remained low as the number of females increased to two ( $p=0.11$ to sire one, $p=0.04$ to sire two infants) but increased substantially as the number of females rose to three. The very high chance of subordinates to father all offspring if the number of females is three $(p=0.46)$ is approximately what would be expected under random mating.

Allowing for an interaction of the number of males and the number of females did not significantly change the model $(\log$ likelihood $=-8.49, G=0.06, d f=1, p=0.81)$. The most important conclusion of this result is that the subordinates' reproductive success remained unaffected by the number of males irrespective of the number of females.

\section{Reproductive skew and relatedness}

To test the relationship between reproductive skew and relatedness, we were interested in the relatedness between dominant males and all subordinates present during the corresponding dominant's tenure. As these males were usually immigrants, their relatedness had to be estimated from relatedness coefficients. Table 5 summarizes all relevant dominant/subordinate pairs along with their corresponding relatedness estimates. For a first classification, we assigned all pairs to one of our discrete relatedness classes using the method suggested by Blouin et al. (1996). In addition, we calculated $z$ scores to obtain an estimate of each coefficient's probability to belong to a different relatedness class. If pairs were classified as unrelated based on the method of Blouin et al., $z$ scores were calculated for the probability that the relatedness coefficients were drawn from the adjacent, lowest relatedness distribution, the SO distribution; if pairs were classified as related (irrespective of the class), $z$ scores were calculated for the probability that the coefficients were drawn from the UR distribution. In ambiguous cases, where possible, we also used information about the males' haplotypes to reach a final assessment of the relatedness of all relevant dominant/subordinate pairs (see footnotes of Table 5 for details).

After having classified all subordinates as being either related or unrelated to the corresponding dominant, we identified three of the 11 infants sired by subordinates as being sired by subordinates related with the dominant. The remaining eight infants were fathered by unrelated subordinates. However, during the different mating seasons, the number of subordinates not related with the dominant was exactly three times as high as the number of relatives. Therefore, under the assumption that all subordinates had equal probabilities of siring offspring, relatedness with the dominant had no significant effect on reproductive success of subordinates (binomial test: exact $p=0.71$ ). If we used the relatedness classification derived solely by relatedness coefficients, the number of infants fathered by relatives was slightly higher (five), but in this case, the number of relatives present during the corresponding mating seasons was also higher (approximately equal to the number of non-relatives). Therefore, in this case as well, the reproductive success of both classes was not different from chance (binomial test: exact $p=0.5$ ).

\section{Discussion}

Redfronted lemurs live in small groups in which the number of males equals or exceeds the number of females. Although males are mostly unrelated to each other, our study revealed that reproductive success is not equally distributed among them, but instead skewed towards dominants. However, the distribution of reproduction within groups could not be explained by models of reproductive skew theory. First, a subordinate's relatedness to the dominant did not affect its reproductive success. Relatives were neither less likely nor

Table 3 Results of the ordered "logit model: $\widehat{\tau}_{1}$ and $\widehat{\tau}_{2}$ represent threshold values in the ordinally scaled dependent variable (see Appendix), $\widehat{\beta}_{\mathrm{m}}$ and $\widehat{\beta}_{\mathrm{f}}$ are maximum likelihood estimates of the regression coefficients relating the number of males and the number of females, respectively, to the proportion of offspring obtained by subordinates

\begin{tabular}{lrllllrr}
\hline & Estimate & SE & Wald & $d f$ & $p$ & $-95 \%$ CI (estimate) & $+95 \%$ CI (estimate) \\
\hline$\widehat{\tau}_{1}$ & 7.34 & 3.92 & 3.51 & 1 & 0.06 & -0.34 & 15.03 \\
$\widehat{\tau}_{2}$ & 8.86 & 4.13 & 4.61 & 1 & 0.03 & 0.77 & 1.96 \\
$\widehat{\beta}_{\mathrm{m}}$ & -0.17 & 0.67 & 0.06 & 1 & 0.8 & -1.49 & 1.15 \\
$\widehat{\beta}_{\mathrm{f}}$ & 3.11 & 1.13 & 7.51 & 1 & 0.006 & 0.89 & 5.33 \\
\hline
\end{tabular}


Table 4 Probabilities of subordinates to have low, medium, or high reproductive success given various numbers of females

\begin{tabular}{llll}
\hline & $x_{\mathrm{f}}=1$ & $x_{\mathrm{f}}=2$ & $x_{\mathrm{f}}=3$ \\
\hline $\operatorname{Pr}\left(\mathrm{y}=\right.$ "low"। $\left.\bar{x}_{m}, x_{f}\right)$ & 0.99 & 0.85 & 0.20 \\
$\operatorname{Pr}\left(\mathrm{y}=\right.$ "medium" | $\left.\bar{x}_{m}, x_{f}\right)$ & - & 0.11 & 0.34 \\
$\operatorname{Pr}\left(\mathrm{y}=\right.$ "high"। $\left.\bar{x}_{m}, x_{f}\right)$ & 0.01 & 0.04 & 0.46
\end{tabular}

The number of males is set to its mean (3.57)

Probabilities are calculated from the parameters derived from the ordered logit model using Eq. 2 (Appendix). more likely to sire offspring than non-relatives (as predicted by the concession and restraint model, respectively). Note, however, that this result is based on small sample size and should therefore only be viewed as preliminary evidence. Second, the number of males in a group did not affect reproductive skew. This result clearly contradicts the tug-ofwar model and, based on the way skew was measured in this study, the concession model as well. Instead, the number of females in a group best predicted the subordinates' probability of siring offspring, which supports the priority-of-access model (Altmann 1962). A summary of the results in relation to our predictions is provided in Table 1.

Table 5 Pairwise relatedness estimates for dominant males with all subordinate males present during their tenures

\begin{tabular}{|c|c|c|c|c|c|c|c|}
\hline Group & Male $^{\mathrm{a}}$ & Estimated $\mathrm{r}$ with dominant & Relatedness with dominant $^{\mathrm{b}}$ & $z^{\mathrm{c}}$ & $p(z)$ or $1-p(z)$ & Haplotype $^{\mathrm{d}}$ & Corrected relatedness $^{\mathrm{e}}$ \\
\hline \multirow[t]{7}{*}{ A1 } & KRK & $* * *$ & $* * *$ & $* * *$ & $* * *$ & 7 & $* * *$ \\
\hline & Rho & -0.07 & UR & -1.25 & 0.11 & 2 & UR \\
\hline & Zyp & 0.07 & SO & 0.92 & 0.18 & 2 & $U^{f}$ \\
\hline & Lem & 0.02 & UR & -0.69 & 0.25 & 1 & UR \\
\hline & Nig & 0 & UR & -0.81 & 0.21 & 10 & UR \\
\hline & Vul & -0.26 & UR & - & - & 1 & UR \\
\hline & Str & 0.46 & $\mathrm{PO} / \mathrm{FS}$ & - & - & 1 & Son \\
\hline \multirow[t]{5}{*}{ A2 } & GIG & $* * *$ & $* * *$ & $* * *$ & $* * *$ & $?$ & $* * *$ \\
\hline & Kos & 0.73 & $\mathrm{PO} / \mathrm{FS}$ & 6.0 & $<0.001$ & $?$ & $\mathrm{PO} / \mathrm{FS}$ \\
\hline & Bal & 0.04 & UR & -0.56 & 0.29 & 11 & UR \\
\hline & Tim & 0.02 & UR & - & - & 3 & UR \\
\hline & Cap & -0.07 & UR & - & - & 1 & UR \\
\hline \multirow[t]{7}{*}{ B1 } & BAL & $* * *$ & $* * *$ & $* * *$ & $* * *$ & 11 & $* * *$ \\
\hline & Sin & 0.22 & HS & 2.08 & 0.02 & 6 & related $^{\mathrm{g}}$ \\
\hline & Kom & 0.12 & $\mathrm{SO}$ & 1.31 & 0.1 & 4 & $\mathrm{UR}^{\mathrm{h}}$ \\
\hline & Sul & 0.09 & SO & 1.08 & 0.14 & 10 & $\mathrm{UR}^{\mathrm{h}}$ \\
\hline & Lom & 0.1 & SO & 1.15 & 0.13 & 3 & $\mathrm{UR}^{\mathrm{h}}$ \\
\hline & Bor & 0.5 & $\mathrm{PO} / \mathrm{FS}$ & - & - & 3 & Son \\
\hline & Hon & 0.1 & SO & 1.15 & 0.13 & 5 & $\mathrm{UR}^{\mathrm{h}}$ \\
\hline \multirow[t]{6}{*}{ B2 } & ALO & $* * *$ & $* * *$ & $* * *$ & $* * *$ & $?$ & $* * *$ \\
\hline & Tha & -0.03 & UR & -1.0 & 0.16 & $?$ & UR \\
\hline & Obi & -0.08 & UR & -1.31 & 0.1 & $?$ & UR \\
\hline & Lao & -0.12 & UR & -1.56 & 0.06 & $?$ & UR \\
\hline & But & -0.08 & UR & -1.31 & 0.16 & $?$ & UR \\
\hline & Tim & 0.06 & SO & - & - & 3 & UR \\
\hline \multirow[t]{5}{*}{$\mathrm{F} 2$} & LAR & $* * *$ & $* * *$ & $* * *$ & $* * *$ & 12 & $* * *$ \\
\hline & Wes & 0.46 & $\mathrm{PO} / \mathrm{FS}$ & 3.92 & $<0.001$ & 11 & Son $^{\mathrm{i}}$ \\
\hline & Key & 0.1 & SO & 1.15 & 0.13 & 11 & $\mathrm{UR}^{\mathrm{j}}$ \\
\hline & Bar & -0.07 & UR & - & - & 1 & UR \\
\hline & Vin & 0.44 & $\mathrm{PO} / \mathrm{FS}$ & - & - & 1 & Son \\
\hline \multirow[t]{2}{*}{$\mathrm{J} 3$} & $\mathrm{CAN}$ & $* * *$ & $* * *$ & $* * *$ & $* * *$ & $?$ & $* * *$ \\
\hline & Kir & 0.59 & $\mathrm{PO} / \mathrm{FS}$ & 4.92 & $<0.001$ & $?$ & $\mathrm{PO} / \mathrm{FS}$ \\
\hline
\end{tabular}

${ }^{\text {a }}$ Dominant males in capital letters, subordinates that sired offspring in italic

${ }^{\mathrm{b}}$ Classification based on the method of Blouin et al. (1996)

${ }^{\mathrm{c}}$ Calculation of $z$ scores (see main text); $z$ scores were not calculated if true relatedness was known from pedigrees.

${ }^{\mathrm{d}}$ Haplotypes taken from Wimmer and Kappeler (2002) and Wimmer (2000), therefore not available for all males

${ }^{\mathrm{e}}$ Reclassification based on pedigree information or on assessments described below

${ }^{\mathrm{f}}$ High probability that $r$ was drawn from UR distribution, different haplotype than dominant, therefore probably unrelated

${ }^{\mathrm{g}}$ Very low probability that $r$ was drawn from UR distribution, albeit different haplotype than dominant. Rare case of paternal half sibs with unrelated mothers?

${ }^{\mathrm{h}}$ Dominant male BAL had high relatedness coefficients with all subordinates, probably due to BAL possessing some rare alleles. However, all subordinates had different haplotypes than BAL, thus probably all unrelated.

${ }^{\mathrm{i}}$ Very high $r$, suggesting either brothers or father/son, however, different haplotypes. Therefore, Wes probably LARs son

${ }^{\mathrm{j}}$ Different haplotype than dominant, at the same time highly related with Wes (not shown). Thus, Wes and Key probably brothers, but Key not sired by LAR, therefore unrelated. 
According to the priority-of-access model, it is not the mere number of females within a group but the number of synchronously receptive females that predict a subordinate male's prospects to mate. In support of this prediction, Charpentier et al. (2005) found that the probability of dominant male mandrills (Mandrillus sphinx) to sire offspring indeed decreased as the number of simultaneously tumescent females increased (but see Engh et al. 2002; Kutsukake and Nunn 2006). In our study, detailed data on female mating synchrony were not available, but, given the highly seasonal reproduction of redfronted lemurs, some degree of estrous overlap between females seems likely (see Ostner and Kappeler 2004). In contrast, in red howler monkeys (Alouatta seniculus), which exhibit a similar social organization, but in which reproduction is asynchronous, reproductive skew among males is very high with dominant males fathering all offspring (Pope 1990).

In addition to the number of synchronously receptive females, the priority-of-access model also predicts that a subordinate's rank influences its reproductive success. Detailed data on subordinate rank were not available for all group years; in addition, the low number of infants born per birth season and the low probability of subordinates to sire offspring precluded a test of this prediction at the reproductive level. For a more complete understanding of the proximate mechanisms underlying the observed pattern of reproductive skew, it may therefore be more promising to test this prediction of the priority-of-access model with data on mating skew.

In accordance with the priority-of-access model, our statistical model estimated that subordinates had roughly zero probability of siring offspring if only one female was present in the group. This probability remained low if groups contained two females, but markedly increased as the number of females increased to three, reaching a level that would be expected if all males (including the dominant) had equal probabilities of siring offspring. We believe that this estimate is an overestimation by our model because in three cases where groups comprised three females, only one infant survived until a tissue sample could be taken, and in each case, this infant was sired by a subordinate, resulting in "high" reproductive success of subordinates in the respective group years. It is unlikely, however, that the infants conceived by the remaining females (but that did not survive) were also sired by subordinates, in which case "medium" reproductive success of subordinates would have been a more realistic classification. This example illustrates the high susceptibility to chance effects of small sample sizes in the study of reproductive skew. This problem is probably relevant whenever studies aim to measure reproductive skew on a year-by-year basis in species with low reproductive rates. The positive relationship between the number of females and the subordinates' reproductive success, however, remained unchanged by this finding (as confirmed by a "standard" logistic regression in which the subordinates' reproductive success was dichotomous instead of ordinally scaled; unpublished results).

Compared to the priority-of-access model, reproductive skew theory performed rather poorly in explaining variation in male reproductive success in redfronted lemurs. In accordance with our study, most tests of reproductive skew theory previously conducted with vertebrates concluded that dominants usually lack control over the allocation of reproduction (e.g., Clutton-Brock et al 2001; Williams 2004). Some studies reported that female estrous overlap (Charpentier et al. 2005) or female choice (Engh et al. 2002; Widdig et al. 2004) affected reproductive skew among males, which led the authors to conclude that "limited control" models best account for the observed pattern of the partition of reproduction. However, it remained unclear which models these authors mean because rejection of the concession model does not necessarily mean acceptance of an alternative reproductive skew model, and if empirical results point to a different direction (e.g., the priority-ofaccess model), they should not be used to evaluate reproductive skew theory. For example, the finding that a dominant lacks control does not necessarily provide support for the "limited control" models of reproductive skew theory (cf. Kappeler and Schäffler 2008). Moreover, as this term summarizes models as different as the restraint- and the tug-of-war model, we recommend avoiding it at all and sticking more closely to the original models instead of using some oversimplifying dichotomy.

Clearly, however, the concession model failed to provide an explanation for the partition of reproduction among male redfronted lemurs. But as these lemurs are long-lived animals, it could be argued that this partition takes place over several breeding seasons (Zink and Reeve 2005). Although we were not able to formally test this assumption, it is unlikely to hold in our population, however, because variation in the subordinates' reproductive success was rather high, which is not consistent with the assumption of a dominant allocating some share of reproduction to all of his subordinates. Thus, based on the results of this study, cooperative forces among males are unlikely to provide an explanation for the evolution of small groups with equal sex ratios in this species. Yet, if the same proximate mechanisms seem to determine male reproductive success in both lemurs and in Old World monkeys, this leaves us with the question of why they differ so strikingly in their social organization? The most parsimonious explanation is probably linked to the highly seasonal reproduction of lemurs. Given a sufficient abundance of resources during most of the year, a surplus of males creates almost no costs to a dominant. But if these males contribute to the prolongation of a dominant's tenure (Ostner and Kappeler 2004), it may benefit the dominant to accept a short phase 
of high competition during which some reproductive opportunities may even be lost. In another lemur species (Propithecus verreauxi), these losses are even less than 10\% (Kappeler and Schäffler 2008). Importantly, combining the results of Ostner and Kappeler (2004) and this study, the net number of males seems to increase the dominant's tenure length but imposes few costs on its reproductive success. Thus, if one-male groups are not stable, a surplus in the number of males beyond a two-male association first and foremost provides benefits but imposes few costs. This is the case whenever access to fertile females, but not the tug-of-war between males, determines male reproductive success, which, in turn, could explain the even or slightly male-biased adult sex ratios.

At this point, it is still premature to completely dismiss reproductive skew theory as an explanatory framework for idiosyncrasies of lemur sociality because by far, not all reproductive skew models could be tested by our study. The finding, however, that a variable incorporated in none of these models, namely the number of females in a group, best predicted the apportionment of reproduction among male redfronted lemurs, casts doubt on the applicability of existing reproductive skew theory to this species. This is probably not only the case for redfronted lemurs, but applies to primates in general, as the social organizations of primates strikingly differ from those of the social insects for which most of these models were originally developed. For example, hymenopteran queens usually mate once at the beginning of their life when sperm of one or several males is stored for later breeding (Thornhill and Alcock 1983; Reeve 1991). Therefore, once an association between queens is formed, the conflict over who lays how many eggs is decided between the queens only. In contrast, in primates, the opposite sex also becomes involved in this conflict. Thus, if reproductive skew among male primates is the focus of interest, the role of females is to be considered as well.

The priority of access model accounts for the role of both sexes better than current reproductive skew theory (but see Cant and Reeve 2002), but some recent empirical evidence also pointed towards the importance of the number of males in the distribution of reproduction, hence supporting the tugof-war model (Kutsukake and Nunn 2006), or a combination of both the priority of access and the tug-of-war model (Boesch et al. 2006). Thus, as neither model alone seems sufficient to explain the pattern of reproductive skew among male primates, their synthesis could help to improve our understanding of sociality and reproductive sharing within this taxon. Kutsukake and Nunn (2008) recently proposed such a synthesis by incorporating the number of males into the priority of access model. Their extended priority of access model therefore provides a valuable first step in the development of models that more closely fit the requirements and realities of primate social organizations.
Acknowledgments We thank the Malagasy Ministère de l'Environnement et des Eaux et Forêts, the Département Biologie Animale de 1'Université d'Antanannarivo, and the Centre de Formation Professionelle Forestière Morondava for authorizing and supporting our long-term research in Kirindy and the late Berthe Rakotosamimanana, Olga Ramilijaona, Daniel Rakotondravony, and Joel Ratsirarson for their support. The equipe DPZ at Kirindy, in particular Tiana Andrianjanahary, Mamitiana Razafindrasamba, Jean-Pierre Ratolojanahary, Nielsen Rabarijaona, Rodin Rasoloarison, and Léonard Razafimanantsoa as well as Edidier and Enafa from Project Beza Mahafaly made indispensable contributions to gidro capture and monitoring. We are also grateful to Manfred Eberle and Christina Oberdieck for their support in the lab to Vanessa Mass for useful discussions, as well as to Jörg Schmidt for his suggestions concerning the ordered logit model. Finally, we would like to thank Charles Nunn, Nobuyuki Kutsukake, and one anonymous referee for constructive comments on a previous version of the manuscript. Funding was provided by the German Research Council (DFG: Ka 1082/1-3 and Ka 1082/9).

Open Access This article is distributed under the terms of the Creative Commons Attribution Noncommercial License which permits any noncommercial use, distribution, and reproduction in any medium, provided the original author(s) and source are credited.

\section{Appendix}

The ordered logit model

The ordered logit model assumes that a latent variable $y^{*}$, ranging from $-\infty$ to $\infty$, underlies the observed dependent variable $y$. With regard to the models tested in this study, in the tug-of-war or priority-of-access model, $y^{*}$ can be interpreted as the dominants inability to monopolize reproduction. As this inability increases, subordinates are more likely to gain a higher proportion of the group's overall reproduction. More precisely, the dependent variable $y$ will switch from a lower (discrete) level to the next higher level if a certain threshold value $\tau$ in $y^{*}$ is reached. A single observation will be of class $\mathrm{k}$ in $\mathrm{y}$ according to the following equation (Long 1997):

$y_{i}=k \quad$ if $\quad \tau_{k-1} \leq y_{i} * \leq \tau_{k} \quad$ for $\quad k=1$ to $\mathrm{j}$

The extreme categories 1 and $j$ are defined by openended intervals with $\tau_{0}=-\infty$ and $\tau_{\mathrm{j}}=\infty$. In terms of our dependent variable,

$$
\begin{aligned}
& y_{i}=\text { "low" } \quad \text { if }-\infty \leq y_{i}{ }^{*} \leq \tau_{1} \\
& y_{i}=\text { "medium" if } \tau_{1} \leq y_{i}{ }^{*} \leq \tau_{2} \\
& y_{i}=\text { "high" } \quad \text { if } \tau_{2} \leq y_{i}{ }^{*} \leq \infty
\end{aligned}
$$

Having defined the thresholds, the probability of observing $k$ in the $i$ th observation, conditional on the independent variables "number of males" $\left(x_{\mathrm{m}}\right)$ and "number 
of females" $\left(x_{\mathrm{f}}\right)$, can be calculated as follows (for a derivation of this equation, see Long 1997, pp 120-122):

$$
\begin{aligned}
\operatorname{Pr}\left(y_{i}=k \mid x_{m i}, x_{f i}\right)= & G\left(\tau_{k}-x_{\mathrm{m} i} \beta_{\mathrm{m}}-x_{\mathrm{f} i} \beta_{\mathrm{f}}\right) \\
& -G\left(\tau_{k-1}-x_{\mathrm{m} i} \beta_{\mathrm{m}}-x_{\mathrm{f} i} \beta_{\mathrm{f}}\right)
\end{aligned}
$$

Estimates of the threshold values and the regression coefficients $\left(\beta_{\mathrm{m}}\right.$ and $\left.\beta_{\mathrm{f}}\right)$ are obtained from all observations using maximum likelihood estimation. Further, assuming that the error distribution of this estimation is logistic, $G$ can be substituted with the cumulative density function of the standard logistic distribution,

$G(\mathrm{q})=\frac{\exp (\mathrm{q})}{1+\exp (\mathrm{q})}$,

and thus,

$$
\begin{aligned}
\operatorname{Pr}\left(y=k \mid x_{\mathrm{m}}, x_{\mathrm{f}}\right)= & \frac{\exp \left(\widehat{\tau}_{\mathrm{m}}-x_{\mathrm{m}} \widehat{\beta}_{\mathrm{m}}-x_{\mathrm{f}} \widehat{\beta}_{\mathrm{f}}\right)}{1+\exp \left(\widehat{\tau}_{\mathrm{m}}-x_{\mathrm{m}} \widehat{\beta}_{\mathrm{m}}-x_{\mathrm{f}} \widehat{\beta}_{\mathrm{f}}\right)} \\
& -\frac{\exp \left(\widehat{\tau}_{\mathrm{m}-1}-x_{\mathrm{m}} \widehat{\beta}_{\mathrm{m}}-x_{\mathrm{f}} \widehat{\beta}_{\mathrm{f}}\right)}{1+\exp \left(\widehat{\tau}_{\mathrm{m}-1}-x_{\mathrm{m}} \widehat{\beta}_{\mathrm{m}}-x_{\mathrm{f}} \widehat{\beta}_{\mathrm{f}}\right)},
\end{aligned}
$$

in which $\widehat{\tau}$ and $\widehat{\beta}$ are maximum likelihood estimates of $\tau$ and $\beta$ (see Eq. 1).

\section{References}

Alberts SC, Watts HE, Altmann J (2003) Queuing and queue-jumping: long-term patterns of reproductive skew in male savannah baboons, Papio cynocephalus. Anim Behav 65:821-840

Altmann SA (1962) A field study of the sociobiology of the rhesus monkey, Macaca mulatta. Ann N Y Acad Sci 102:338435

Andelman SJ (1986) Ecological and social determinants of cercopithecine mating patterns. In: Rubenstein DI, Wrangham RW (eds) Ecological aspects of social evolution. Princeton University Press, Princeton, pp 201-216

Bateman AJ (1948) Intra-sexual selection in Drosophila. Heredity 2:349-368

Boesch C, Kohou G, Néné H, Vigilant L (2006) Male competition and paternity in wild chimpanzees of Taï forest. Am J Phys Anthropol 130:103-115

Blouin MS (2003) DNA-based methods for pedigree reconstruction and kinship analysis in natural populations. Trends Ecol Evol 18:503-511

Blouin MS, Parsons M, Lacaille V, Lotz S (1996) Use of microsatellite loci to classify individuals by relatedness. Mol Ecol 5:393-401

Boskoff KJ (1978) The oestrus cycle of the brown lemur, Lemur fulvus. J Reprod Fertil 54:313-318

Cant MA, Reeve HK (2002) Female control of the distribution of paternity in cooperative breeders. Am Nat 160:602-611
Charpentier M, Peignot P, Hossart-McKey M, Gimenez O, Setchell JM, Wickings EJ (2005) Constraints on control: factors influencing reproductive success in male mandrills (Mandrillus sphinx). Behav Ecol 16:614-623

Clutton-Brock TH (1989) Mammalian mating systems. Proc R Soc Lond B 236:339-372

Clutton-Brock TH (1998) Reproductive skew, concessions and limited control. Trends Ecol Evol 13:288-292

Clutton-Brock TH, Brotherton PNM, Russell AF, O'Riain MJ, Gaynor D, Kansky R, Griffin A, Manser M, Sharpe L, McIlrath GM, Small T, Moss A, Monfort S (2001) Cooperation, control, and concession in meekat groups. Science 291:478-481

Cords M (2000) The number of males in guenon groups. In: Kappeler PM (ed) Primate males: Causes and consequences of group composition. Cambridge University Press, Cambridge, pp 84-96

Crook JH, Gartlan JC (1966) Evolution of primate societies. Nature 210:1200-1203

Emlen ST, Oring LW (1977) Ecology, sexual selection, and the evolution of mating systems. Science 197:215-223

Engh AL, Funk SM, van Horn RC, Scribner KT, Bruford MW, Libants S, Szykman M, Smale L, Holekamp KE (2002) Reproductive skew among males in a female dominated mammalian society. Behav Ecol 13:193-200

Hannonen M, Sundström L (2003) Reproductive sharing among queens in the ant Formica fusca. Behav Ecol 14:870-875

Haydock J, Koenig WD (2003) Patterns of reproductive skew in the polygynandrous acorn woodpecker. Am Nat 162:277-289

Heg D, Bergmüller R, Bonfils D, Otti O, Bachar Z, Burri Z, Heckel G, Taborsky M (2006) Cichlids do not adjust reproductive skew to the availability of independent breeding options. Behav Ecol $17: 419-429$

Jamieson IG (1997) Testing reproductive skew models in a communally breeding bird, the pukeko, Porphyrio porphyrio. Proc R Soc Lond B 264:335-340

Jekielek J, Strobeck C (1999) Characterization of polymorphic brown lemur (Eulemur fulvus) microsatellite loci and their amplification in the family Lemuridae. Mol Ecol 8:895-906

Johnstone RA (2000) Models of reproductive skew: A review and synthesis. Ethology 106:5-26

Johnstone RA, Cant MA (1999) Reproductive skew and the treat of eviction: a new perspective. Proc R Soc Lond B 266:275279

Johnstone RA, Woodroffe R, Cant MA, Wrigth J (1999) Reproductive skew in multimember groups. Am Nat 153:315-331

Kappeler PM (1999) Primate socioecology: new insights from males. Naturwissenschaften 85:18-29

Kappeler PM (2000) Causes and consequences of unusual sex ratios among lemurs. In: Kappeler PM (ed) Primate males: causes and consequences of group composition. Cambridge University Press, Cambridge, pp 55-63

Kappeler PM, Schäffler L (2008) The lemur syndrome unresolved: extreme male reproductive skew in sifakas (Propithecus verreauxi), a sexually monomorphic primate with female dominance. Behav Ecol Sociobiol (in press) DOI 10.1007/s00265-007-0528-6

Kokko H, Johnstone RA (1999) Social queuing in animal societies: a dynamic model of reproductive skew. Proc R Soc Lond B 265:571-578

Kokko H, Mackenzie A, Reynolds JD, Lindström J, Sutherland WJ (1999) Measures of inequality are not equal. Am Nat 72:358-382

Kutsukake N, Nunn CL (2006) Comparative tests of reproductive skew in male primates: the role of demographic factors and incomplete control. Behav Ecol Sociobiol 60:695-706

Kutsukake N, Nunn CL (2008) The causes and consequences of reproductive skew in male primates. In: Hager R, Jones CB (eds) Reproductive skew in vertebrates: proximate and ultimate factors. Cambridge University Press, Cambridge 
Long JS (1997) Regression models for categorical and limited dependent variables. Sage Publications, Thousand Oaks

Marshall TC, Slate J, Kruuk LEB, Pemberton JM (1998) Statistical confidence for likelihood-based paternity inference in natural populations. Mol Ecol 7:639-655

McRae SB (1996) Family values: costs and benefits of communal nesting in the moorhen. Anim Behav 52:225-245

Nonacs P (2003) Measuring the reliability of skew indices: is there one best index? Anim Behav 65:615-627

Nonacs P (2006) The rise and fall of transactional skew theory in the model genus Polistes. Ann Zool Fennici 43:443-445

Nonacs P (2007) Tug-of-war has no borders: it is the missing model in reproductive skew theory. Evolution 61:1244-1250

Nunn CL (1999) The number of males in primate groups: a comparative test of the socioecological model. Behav Ecol Sociobiol 46:1-13

Ostner J (2004) Sex-specific reproductive strategies of redfronted lemurs (Eulemur fulvus rufus, Primates, Lemuridae). PhD, University of Würzburg, Würzburg

Ostner J, Kappeler PM (1999) Central males instead of multiple pairs in redfronted lemurs, Eulemur fulvus rufus (Primates, Lemuridae)? Anim Behav 58:1069-1078

Ostner J, Kappeler PM (2004) Male life history and the unusual sex ratios of redfronted lemur (Eulemur fulvus rufus) groups. Anim Behav 67:249-259

Packer CR, Herbst L, Pusey AE, Bygott JD, Hanby JP, Cairns SJ, Borgerhoff-Mulder M (1988) Reproductive success in lions. In: Clutton-Brock TH (ed) Reproductive success. University of Chicago Press, Chicago, pp 363-383

Pope T (1990) The reproductive consequences of male cooperation in the red howler monkey: paternity exclusion in multi-male and single-male troops using genetic markers. Behav Ecol Sociobiol 27:439-446

Queller DC, Goodnight KF (1989) Estimating relatedness using genetic markers. Evolution 43:258-275

Reeve HK (1991) Polistes. In: Ross KG, Matthews RW (eds) The social biology of wasps. Cornell University Press, Ithaca, pp 99148

Reeve HK (1998) Game theory, reproductive skew, and nepotism. In: Dugatkin L, Reeve HK (eds) Game theory and animal behaviour. Oxford University Press, Oxford, pp 118-145

Reeve HK, Ratnieks FLW (1993) Queen-queen conflict in polygynous societies: Mutual tolerance and reproductive skew. In: Keller L (ed) Queen number and sociality in insects. Oxford University Press, Oxford, pp 45-85

Reeve HK, Emlen ST (2000) Reproductive skew and group size: an N-person staying incentive model. Behav Ecol 11:640-647

Reeve HK, Keller L (2001) Tests of reproductive skew models in social insects. Ann Rev Entomol 46:347-385
Reeve HK, Shen SF (2006) A missing model in reproductive skew theory: the bordered tug-of-war. Proc Natl Acad Sci U S A 103:8430-8434

Reeve HK, Emlen ST, Keller L (1998) Reproductive sharings in animal societies: reproductive incentives or incomplete control by dominant breeders? Behav Ecol 9:267-278

Sorg J, Ganzhorn J, Kappeler PM (2003) Forestry and research in the Kirindy Forest/Centre de Formation Professionnelle Forestière. In: Goodman S, Benstead J (eds) The natural history of Madagascar. University of Chicago Press, Chicago, pp 1512-1519

Stiver KA, Dierkes P, Taborsky M, Gibbs HL, Balshine S (2005) Relatedness and helping in fish: examining the theoretical predictions. Proc R Soc Lond B 272:1593-1599

Thornhill R, Alcock J (1983) The evolution of insect mating systems. Harvard University Press, Cambridge

Trivers RL (1972) Parental investment and sexual selection. In: Campbell B (ed) Sexual selection and the descent of man, 18711971. Heinemann, London, pp 136-179

van de Casteele T, Galbusera P, Matthysen E (2001) A comparison of microsatellite-based pairwise relatedness estimators. Mol Ecol 10:1539-1549

van Schaik CP, van Noordwijk MA (1989) The special role of Cebus monkeys in predation avoidance and its effect on group composition. Behav Ecol Sociobiol 24:265-276

van Schaik CP, Kappeler PM (1996) The social systems of gregarious lemurs: lack of convergence with anthropoids due to evolutionary disequilibrium? Ethology 102:915-941

Vehrencamp SL (1983a) Optimal degree of skew in cooperative societies. Am Zool 23:327-335

Vehrencamp SL (1983b) A model for the evolution of despotic versus egalitarian societies. Anim Behav 31:667-682

Widdig A, Bercovitch FB, Streich WJ, Sauermann U, Nuernberg P, Krawczak M (2004) A longitudinal analysis of reproductive skew in male macaques. Proc R Soc Lond B 271:819-826

Williams DA (2004) Female control of reproductive skew in cooperatively breeding brown jays (Cyanocorax morio). Behav Ecol Sociobiol 55:370-380

Wimmer B (2000) Untersuchungen der Paarungssysteme und der Populationsstruktur von Lemuren an Coquerels Zwergmaki (Mirza coquereli), dem grauen Mausmaki (Microcebus murinus), dem Rotstirnmaki (Eulemur fulvus rufus) und dem Larvensifaka (Propithecus verreauxi verreauxi). $\mathrm{PhD}$, University of Würzburg, Würzburg

Wimmer B, Kappeler PM (2002) The effects of sexual selection and life history on the genetic structure of redfronted lemur, Eulemur fulvus rufus, groups. Anim Behav 64:557-568

Zink AG, Reeve HK (2005) Predicting the temporal dynamics of reproductive skew and group membership in communal breeders. Behav Ecol 16:880-888 